\title{
Estimating modes of inter-decadal variability and predictability in coupled climate models
}

\author{
C. S. Frederiksen ${ }^{1} \quad$ X. Quan ${ }^{2} \quad$ X. Zheng ${ }^{3}$ \\ S. Grainger ${ }^{4}$
}

Received 9 February 2017; revised 23 October 2017

\begin{abstract}
A methodology is described that allows a separation of inter-decadal variability into components associated with intra-decadal noise and potentially predictable slow decadal processes. The method is applied to a 1200 year simulation of internal variability of sea surface temperature in a coupled atmosphere-ocean model using parameters and radiative forcing associated with the year 2000. The analysis shows large predictability in the extratropical regions. The two leading modes associated with intra-decadal variability are shown to be related to interannual variability in the El Nino-Southern Oscillation and the Atlantic Multi-decadal Oscillation. The leading four slow modes are shown to
\end{abstract}

Dor:10.21914/anziamj.v58i0.11795, C Austral. Mathematical Soc. 2017. Published 2017-11-08, as part of the Proceedings of the 18th Biennial Computational Techniques and Applications Conference. ISSN 1445-8810. (Print two pages per sheet of paper.) Copies of this article must not be made otherwise available on the internet; instead link directly to the DOI for this article. Record comments on this article via http://journal austms.org.au/ojs/index.php/ANZIAMJ/comment/add/11795/0 
be related to slow decadal variability in the Pacific Decadal Oscillation, the Atlantic Multi-decadal Oscillation and the Arctic Oscillation.

\section{Contents}

1 Introduction

C83

2 Model dataset

C84

3 Methodology

C84

4 Modes of inter-decadal variability

C87

5 Conclusion

C89

References

C91

\section{Introduction}

Recently, Frederiksen et al. [1] reviewed the literature and current state of knowledge regarding decadal to centennial climate variability, and proposed a new methodology for extracting potentially predictable decadal modes. Their methodology was applied to a 1000 year climate simulation of sea surface temperature (SST) over the period 850-1850. Lou et al. [2] used the method to investigate decadal variability in the Northern Hemisphere atmospheric circulation in the same simulation. Both studies were complicated by the presence of changing external radiative forcing. In this paper, we describe the methodology in detail, and apply it to investigate the natural internal decadal variability in a 1200 year simulation using parameters and radiative forcing associated with the year 2000. For an historical perspective on our 
understanding of the dynamics of interdecadal variability the interested reader is referred to the work of $\mathrm{Liu}[3]$.

\section{Model dataset}

The SST data used in this study are from a 1200 year simulation of the Community Earth System Model version 1 (CESM1) (see www.cesm.ucar. edu/models/cesm1.0 for a description of the model). For the length of the simulation, the model was continually cycled using parameters and radiative forcing for the year 2000 with, in particular, observed concentrations of important atmospheric gases $\mathrm{CO}_{2}, \mathrm{~N}_{2} \mathrm{O}$ and $\mathrm{CH}_{4}$ of $368.9 \mathrm{ppmv}, 316.0 \mathrm{ppbv}$ and $1760 \mathrm{ppbv}$. The analysis is global in longitude but restricted between latitudes $60^{\circ} \mathrm{S}$ to $70^{\circ} \mathrm{N}$. The resolution of the data is $2.5^{\circ}$ longitude by approximately $2^{\circ}$ latitude. The data was de-trended to remove the model drift.

\section{Methodology}

Let $x_{d, y}$ and $x_{d, y}^{\prime}$ represent annual mean anomalies in a climate variable, such as SST, in decade $d(d=1, \ldots, D)$ and year $y(y=1, \ldots, 10)$ of the decade, at two different geographical locations. Anomalies are calculated by subtracting the mean of the original data in year $y$ over all decades. Here, it is the inter-decadal variability of the decadal mean anomaly that is the main interest. The decadal mean anomaly in decade $d$ is

$$
x_{d, o}=\frac{1}{10} \sum_{y=1}^{10} x_{d, y} .
$$

A conceptual model for the annual anomalies, for example Frederiksen et al. [1], is

$$
x_{\mathrm{d}, y}=\mu_{\mathrm{d}}+\varepsilon_{\mathrm{d}, y}
$$


where $\mu_{\mathrm{d}}$ is the slow-decadal (SD) or potentially predictable component, associated with slow decadally varying internal dynamics or external forcing on the climate system, and assumed to be constant over the decade. The residual $\varepsilon_{\mathrm{d}, y}$ between $x_{\mathrm{d}, y}$ and $\mu_{\mathrm{d}}$ represents year to year departures from the slow component, or intra-decadal (ID) variability within the decadal and will be referred to as the intra-decadal component. Over all decades this intra-decadal component is assumed to have zero mean. The decadal mean of $x_{\mathrm{d}, y}$ is then $x_{\mathrm{d}, \mathrm{o}}=\mu_{\mathrm{d}}+\varepsilon_{\mathrm{d}, \mathrm{o}}$. Since the annual mean is likely to be unpredictable beyond a year or two, $\varepsilon_{\mathrm{d}, \mathrm{o}}$ is unpredictable at decadal time scales and represents the decadal noise.

The inter-decadal co-variance $\mathrm{V}\left(\mathrm{x}_{\mathrm{d}, \mathrm{o}}, \mathrm{x}_{\mathrm{d}, \mathrm{o}}^{\prime}\right)$ between $\mathrm{x}_{\mathrm{d}, \mathrm{o}}$ and $x_{\mathrm{d}, \mathrm{o}}^{\prime}$ is just the second moment

$$
V\left(x_{d, o}, x_{d, o}^{\prime}\right)=\frac{1}{D-1} \sum_{d=1}^{D}\left(x_{d, o}-x_{o, o}\right)\left(x_{d, o}^{\prime}-x_{o, o}^{\prime}\right),
$$

where $x_{\mathrm{o}, \mathrm{o}}=\frac{1}{\mathrm{D}} \sum_{\mathrm{d}=1}^{\mathrm{D}} x_{\mathrm{d}, \mathrm{o}}$. The aim is then to estimate the decomposition

$$
\mathrm{V}\left(\mathrm{x}_{\mathrm{d}, \mathrm{o}}, x_{\mathrm{d}, \mathrm{o}}^{\prime}\right)=\mathrm{V}\left(\mu_{\mathrm{d}}, \mu_{\mathrm{d}}^{\prime}\right)+\mathrm{V}\left(\varepsilon_{\mathrm{d}, \mathrm{o}}, \varepsilon_{\mathrm{d}, \mathrm{o}}^{\prime}\right),
$$

for the co-variances $V\left(\mu_{\mathrm{d}}, \mu_{\mathrm{d}}^{\prime}\right)$, of the potentially predictable component, and $\mathrm{V}\left(\varepsilon_{\mathrm{d}, \mathrm{o}}, \varepsilon_{\mathrm{d}, \mathrm{o}}^{\prime}\right)$, of the unpredictable component.

The co-variance $\mathrm{V}\left(\varepsilon_{\mathrm{d}, \mathrm{o}}, \varepsilon_{\mathrm{d}, \mathrm{o}}^{\prime}\right)$ of the intra-decadal noise components is equivalent to the expectation $\mathrm{E}\left(\varepsilon_{\mathrm{d}, \mathrm{o}} \varepsilon_{\mathrm{d}, \mathrm{o}}^{\prime}\right)$ because $\varepsilon_{\mathrm{o}, \mathrm{o}}=0$ at all locations. The noise components are assumed to be Auto-regressive One (AR1) [1] so that

$$
\varepsilon_{\mathrm{d}, y}=\alpha \varepsilon_{\mathrm{d}, y-1}+\eta_{\mathrm{d}, \mathrm{y}},
$$

where $\eta_{\mathrm{d}, y}$ is the innovation, and is assumed stationary with mean zero and statistically independent of each other and $\varepsilon_{\mathrm{d}, \mathrm{y}} ; \alpha$ is the estimated autocorrelation of $x_{\mathrm{d}, y}$ over all years and decades after removing variability greater than 10 years. An estimate of $\mathrm{E}\left(\varepsilon_{\mathrm{d}, \mathrm{o}} \varepsilon_{\mathrm{d}, \mathrm{o}}^{\prime}\right)$ can be derived as follows. Consider

$$
a \equiv \frac{1}{9 D} \sum_{d=1}^{D} \sum_{y=1}^{9}\left(x_{d, y+1}-x_{d, y}\right)\left(x_{d, y+1}^{\prime}-x_{y, d}^{\prime}\right) .
$$


Using (2) and (5), a can be rewritten as

$$
\begin{array}{rl}
a & E\left(\left(\varepsilon_{\mathrm{d}, y+1}-\varepsilon_{\mathrm{d}, y}\right)\left(\varepsilon_{\mathrm{d}, y+1}^{\prime}-\varepsilon_{\mathrm{d}, y}^{\prime}\right)\right) \\
= & E\left(\varepsilon_{\mathrm{d}, y+1} \varepsilon_{\mathrm{d}, y+1}^{\prime}\right)-E\left(\varepsilon_{\mathrm{d}, y+1} \varepsilon_{\mathrm{d}, y}^{\prime}\right)-E\left(\varepsilon_{\mathrm{d}, y} \varepsilon_{\mathrm{d}, y+1}^{\prime}\right)+E\left(\varepsilon_{\mathrm{d}, y} \varepsilon_{\mathrm{d}, y}^{\prime}\right) \\
= & E\left(\varepsilon_{\mathrm{d}, y+1}^{\prime} \varepsilon_{\mathrm{d}, y+1}^{\prime}\right)-E\left(\left(\alpha \varepsilon_{\mathrm{d}, y}+\eta_{\mathrm{d}, y+1}\right) \varepsilon_{\mathrm{d}, y}^{\prime}\right)-E\left(\varepsilon_{\mathrm{d}, y}\left(\alpha^{\prime} \varepsilon_{\mathrm{d}, y}^{\prime}+\eta_{\mathrm{d}, y+1}^{\prime}\right)\right) \\
& +\mathrm{E}\left(\varepsilon_{\mathrm{d}, y} \varepsilon_{\mathrm{d}, y}^{\prime}\right) \\
= & \left(2-\alpha-\alpha^{\prime}\right) E\left(\varepsilon_{\mathrm{d}, y} \varepsilon_{\mathrm{d}, y}^{\prime}\right),
\end{array}
$$

using the AR1 assumption. For convenience, let $\gamma=\mathrm{E}\left(\varepsilon_{\mathrm{d}, \mathrm{y}} \varepsilon_{\mathrm{d}, \mathrm{y}}^{\prime}\right)$, such that,

$$
\gamma=\frac{a}{\left(2-\alpha-\alpha^{\prime}\right)}
$$

with $a, \alpha$ and $\alpha^{\prime}$ estimated from the original data $x_{d, y}$. It then follows, by definition, that

$$
\begin{aligned}
E\left(\varepsilon_{\mathrm{d}, \mathrm{o}} \varepsilon_{\mathrm{d}, \mathrm{o}}^{\prime}\right)= & \mathrm{E}\left(\frac{1}{10} \sum_{y=1}^{10} \varepsilon_{\mathrm{d}, \mathrm{y}} \frac{1}{10} \sum_{y^{\prime}=1}^{10} \varepsilon_{\mathrm{d}, \mathrm{y}^{\prime}}^{\prime}\right) \\
= & \frac{1}{100} \sum_{y=1}^{9} \sum_{y^{\prime}=y+1}^{10} \mathrm{E}\left(\varepsilon_{\mathrm{d}, y} \varepsilon_{\mathrm{d}, y^{\prime}}^{\prime}\right)+\frac{1}{100} \sum_{y^{\prime}=1}^{9} \sum_{y=y^{\prime}+1}^{10} \mathrm{E}\left(\varepsilon_{\mathrm{d}, y} \varepsilon_{\mathrm{d}, y^{\prime}}^{\prime}\right) \\
& +\frac{1}{100} \sum_{y=1}^{10} \mathrm{E}\left(\varepsilon_{\mathrm{d}, y} \varepsilon_{\mathrm{d}, \mathrm{y}}^{\prime}\right)
\end{aligned}
$$

and using the AR1 assumption (5) this can be expressed as

$$
\begin{aligned}
\mathrm{E}\left(\varepsilon_{\mathrm{d}, \mathrm{o}} \varepsilon_{\mathrm{d}, \mathrm{o}}^{\prime}\right) & =\frac{\gamma}{100}\left[\sum_{y=1}^{9} \sum_{y^{\prime}=\mathrm{y}+1}^{10} \alpha^{\left(y^{\prime}-y\right)}+\sum_{y^{\prime}=1}^{9} \sum_{y=y^{\prime}+1}^{10}\left(\alpha^{\prime}\right)^{\left(y-y^{\prime}\right)}+\sum_{y=1}^{10} 1\right] \\
& =\frac{\gamma}{100}\left[\sum_{y=1}^{9}(10-y)\left(\alpha^{y}+\left(\alpha^{\prime}\right)^{y}\right)+10\right] \\
& \equiv \mathrm{V}\left(\varepsilon_{\mathrm{d}, \mathrm{o}}, \varepsilon_{\mathrm{d}, \mathrm{o}}^{\prime}\right) .
\end{aligned}
$$


Hence, using equation(4),

$$
\mathrm{V}\left(\mu_{\mathrm{d}}, \mu_{\mathrm{d}}^{\prime}\right) \approx \mathrm{V}\left(x_{\mathrm{d}, \mathrm{o}}, x_{\mathrm{d}, \mathrm{o}}^{\prime}\right)-\mathrm{V}\left(\varepsilon_{\mathrm{d}, \mathrm{o}}, \varepsilon_{\mathrm{d}, \mathrm{o}}^{\prime}\right) .
$$

We define a measure of potential inter-decadal predictability $p$ at each geographical location as the fraction of the total decadal variance that is attributable to the slow decadal component. That is

$$
p=\frac{V\left(\mu_{d}, \mu_{d}\right)}{V\left(x_{d, o}, x_{d, o}^{\prime}\right)} .
$$

Equations (3), (10) and (11) can be used to construct the co-variance matrices of each component. The eigenmodes and eigenvalues, as defined by von Storch and Zwiers [4], of each covariance matrix, give, respectively, the patterns and decadal variance explained by each mode. The associated time-series of each mode is just the projection of the original SST data onto each pattern. The eigenmodes for the intra-decadal and slow-decadal components will be designated as ID-modes and SD-modes, respectively.

\section{Modes of inter-decadal variability}

Figure 1(a) shows the square root of the estimated inter-decadal variance in SST and shows large inter-decadal variability in the extratropical Northern Hemisphere, the tropical Pacific Ocean, and to a lesser extent in the Southern Hemisphere. The fraction of the total variance (i.e., potential predictability) that is attributable to the slow decadal component is shown in Figure 1(d), and indicates most of the total variance in the tropical Pacific and Atlantic is related to the intra-decadal component, and is therefore inherently unpredictable. However, in the extratropics of both hemispheres a substantial fraction of the total variance is associated with the slow component and is therefore potentially predictable.

The two leading ID-modes are shown in Figure 1(b) and (c), and explain $38.2 \%$ and $16.1 \%$ of the inter-decadal variance in the intra-decadal component. 
Figure 1: (a)Total decadal standard deviation in $\operatorname{SST}(\mathrm{K}),(\mathrm{b})$ and (c) the 2 leading ID-modes, (d) the estimated potential decadal predictability (fraction), (e) the intra-decadal covariance between SST and NINO3 index $\left(\mathrm{K}^{2}\right)$, (f) intradecadal covariance between the SST and the AMO index $\left(\mathrm{K}^{2}\right)$.

(a)

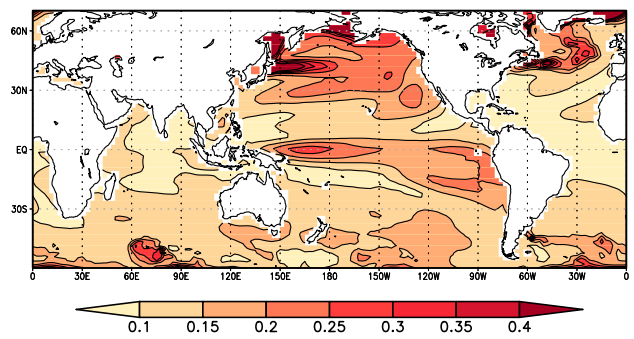

(b) ID-MODE 1

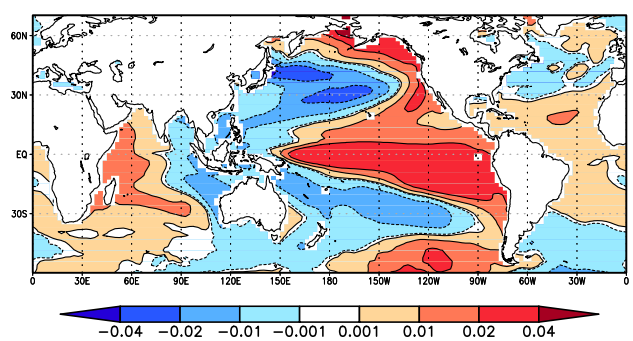

(c) ID-MODE 2

$16.1 \%$

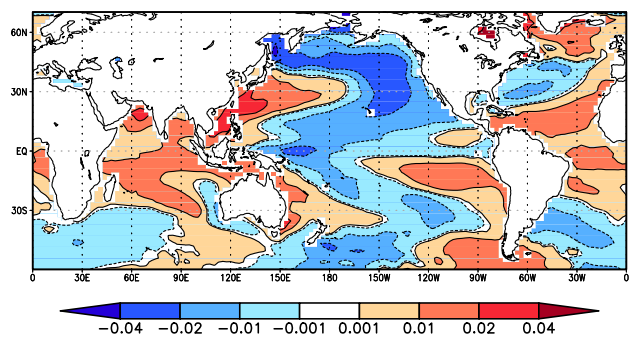

(d) Potential Decadal Predictability

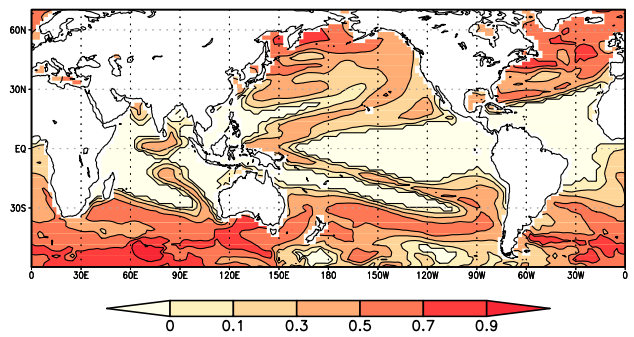

(e)Intradecadal Covariance SST and NINO3

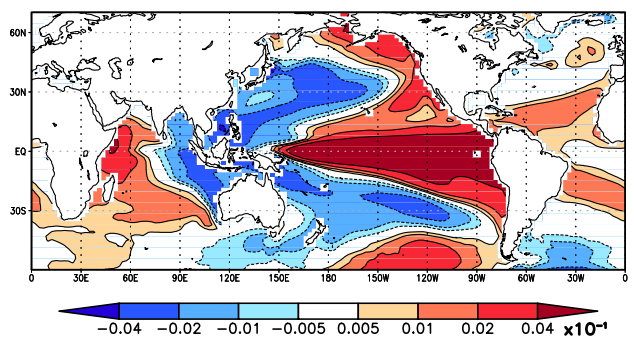

(f) Intradecadal Covariance SST and AMOI

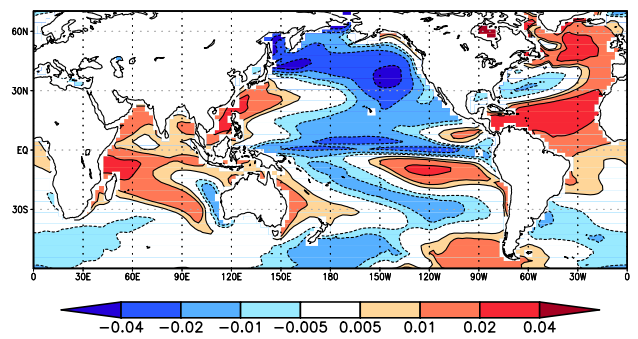


Consistent with Figure 1(d), ID-mode 1 shows large loading in the tropical Pacific and Atlantic Oceans, where there is virtually no potential decadal predictability. The pattern of ID-mode 1 is very similar to the dominant mode of inter-annual variability associated with the El Nino-Southern Oscillation (ENSO). This is confirmed in Figure 1(e) which shows the inter-decadal covariance between the intra-decadal components (10) of SST and the NINO3 index, used to describe ENSO and defined as the time-series of the SST anomaly in the region $5^{\circ} \mathrm{S}-5^{\circ} \mathrm{N}, 150^{\circ} \mathrm{W}-150^{\circ} \mathrm{W}$.

ID-mode 2 appears to be associated with the inter-decadal variability of the intra-decadal component of the Atlantic Multi-decadal Oscillation (AMO) and this is confirmed in Figure 1(f). This shows the inter-decadal covariance between the intra-decadal components of SST and the AMO index, defined as the time-series of the SST anomaly in the region $0^{\circ} \mathrm{S}-60^{\circ} \mathrm{N}, 0^{\circ} \mathrm{W}-80^{\circ} \mathrm{W}$.

Figure 2(a)-(d) shows the four leading SD-modes which explain 19.9\%, 17.6\%, $12.2 \%$ and $7.3 \%$, respectively of the decadal variance in the slow component. Also shown in Figure 2(e)-(g) is the inter-decadal covariance between the slow decadal components (11) of SST and the time-series of the Pacific Decadal Oscillation (PDO), the AMO and the Artic Oscillation (AO) indices. The PDO index is defined as the leading mode of SST variability in the region $20^{\circ} \mathrm{N}-70^{\circ} \mathrm{N}, 110^{\circ} \mathrm{E}-199^{\circ} \mathrm{W}$; the $\mathrm{AO}$ index is the time-series of the mean sea level pressure anomalies in the region $35^{\circ} \mathrm{N}-65^{\circ} \mathrm{N}$. Pattern correlations (PC) between the SD-modes and the slow covariance patterns suggests that SD-mode 1 is mainly associated with the PDO ( $\mathrm{PC}=0.69)$; SD-modes 2 and 3 with the $\mathrm{AMO}(\mathrm{PC}=0.63$ and 0.46 , respectively); $\mathrm{SD}-$ mode 4 with the $\mathrm{AO}(\mathrm{PC}=0.58)$.

\section{Conclusion}

The methodology successfully separates the signal and the noise in decadal variability of climate fields. Under year 2000 conditions, the decadal variability associated with the intra-decadal noise component is shown to be related to 
Figure 2: (a)-(d) the leading four SD-modes, (e)-(g) the slow covariance between SST and the PDO, AMO and AO indices, respectively.

(a) SD-MODE 1

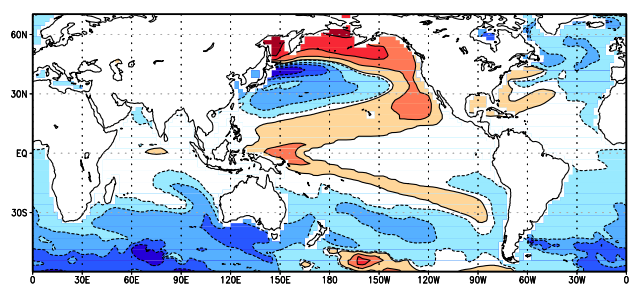

(b)
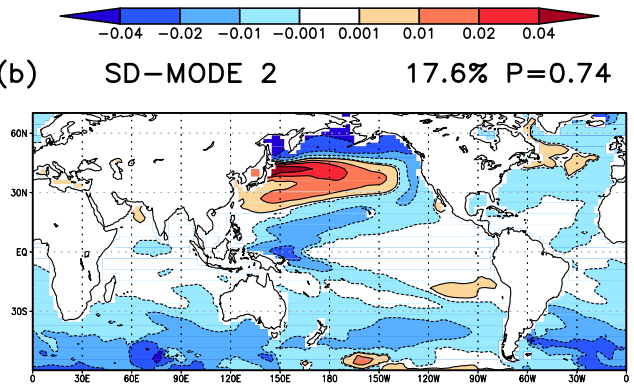

(c) SD-MODE 3

$12.2 \% P=0.72$

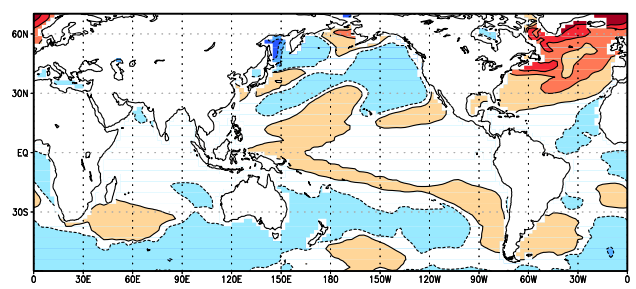

\begin{tabular}{ll|l|l|l|ll|lll}
\hline & & & & & & & & & \\
\hline-0.04 & -0.02 & -0.01 & -0.001 & 0.001 & 0.01 & 0.02 & 0.04
\end{tabular}

(d) SD-MODE 4

7.3\% $P=0.70$

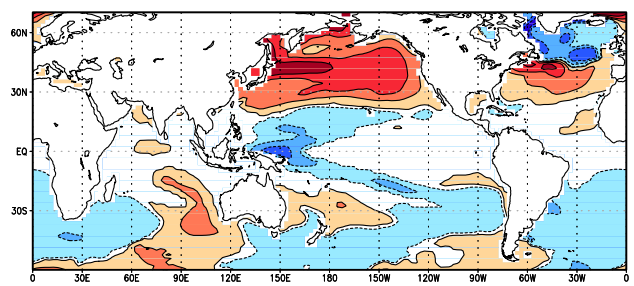

(e) Slow Covariance SST and PDO

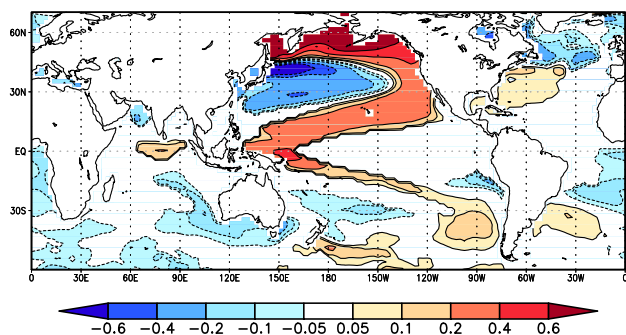

(f)

Slow Covariance SST and AMO
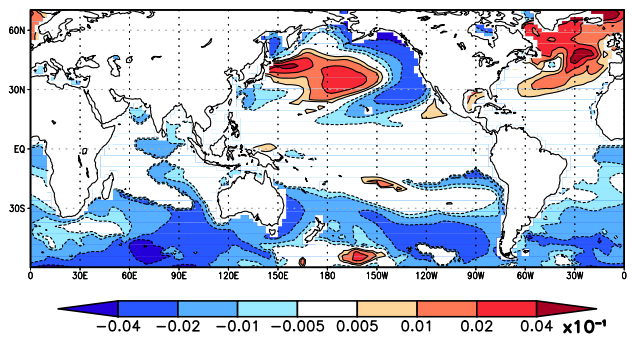

(g) Slow Covariance SST and AOI

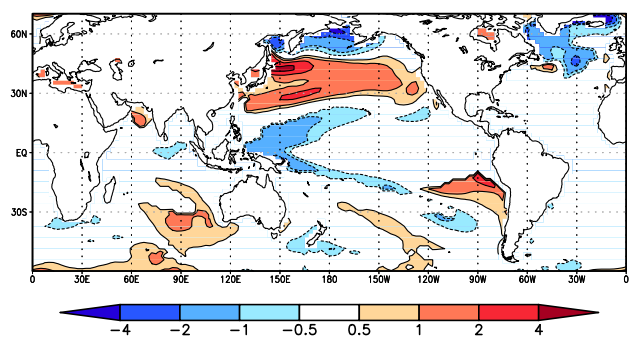


interannual variability in ENSO and the AMO. The SD-modes are shown to be related to decadal variability in the slow components of the PDO, the AMO and the AO, consistent with earlier studies of the period 850-1850 [1, 2].

\section{References}

[1] C. S. Frederiksen, X. Zheng and S. Grainger. Simulated modes of inter-decadal predictability in sea surface temperature. Clim. Dyn., 46:2231-2245, 2016. doi:10.1007/s00382-015-2699-6. C83, C84, C85, C91

[2] J. Lou, X. Zheng, C. S. Frederiksen, H. Liu, S. Grainger and K. Ying. Simulated decadal modes of the $\mathrm{NH}$ atmospheric circulation arising from intra-decadal variability, external forcing and slow-decadal climate processes. Clim. Dyn.,48:2635-2652, 2016. doi:10.1007/s00382-016-3229-x C83, C91

[3] Z. Liu. Dynamics of interdecadal climate variability: a historical perspective. J. Clim., 25:143-162, 2012. doi:10.1175/2011JCLI3980.1 C84

[4] H. von Storch and F. W. Zwiers. Statistical Analysis in Climate Research. Cambridge University Press, 484pp, 2001. C87

\section{Author addresses}

1. C. S. Frederiksen, Bureau of Meteorology and Monash University, Melbourne, Australia.

mailto:c.frederiksen@bom.gov.au

2. X. Quan, University of Colorado, Boulder, UsA.

3. X. Zheng, Beijing Normal University, Beijing, ChInA. 
4. S. Grainger, Bureau of Meteorology, Melbourne, Australia. 